\title{
Optimization of Nano-Hydroxyapatite/Poly(lactic-co-glycolic acid) Coatings on Magnesium Substrates using One-Step Electrophoretic Deposition
}

\author{
Qiaomu Tian ${ }^{1}$, Laura Rivera-Castaneda ${ }^{1}$, Huinan Liu ${ }^{1,2, *}$
}

1. Department of Bioengineering, University of California, Riverside, USA

2. Materials Science and Engineering Program, University of California, Riverside, USA

\author{
*Corresponding Author: \\ Huinan Liu, PhD \\ Associate Professor \\ Department of Bioengineering \\ Materials Science and Engineering Program \\ Stem Cell Center \\ University of California at Riverside \\ 900 University Avenue \\ Riverside, CA 92521 \\ Office: MSE 227 \\ Phone: 9518272944 \\ Fax: 9518276416 \\ Email: huinan.liu@ucr.edu
}




\begin{abstract}
:
This study focuses on optimizing nanocomposite coatings of nanophase hydroxyapatite (nHA) and poly(lactic-co-glycolic acid) (PLGA) on magnesium (Mg) substrates using one-step electrophoretic deposition (EPD). The nHA, PLGA and Mg are all biodegradable materials in the human body, which make them favorable for temporary implant applications. $\mathrm{Mg}$ and its alloys possess the elastic modulus and strength comparable to cortical bone, and thus reduce the detrimental effects of stress-shielding while providing necessary strength for load-bearing applications. The nHA is an attractive coating material for bone healing due to its osteoconductivity. PLGA promotes coating adhesion, and may neutralize the alkaline degradation products of Mg substrates. The nHA_PLGA composite coatings were deposited on Mg substrates using EPD with acetone as the electrolyte solvent. The parameters for EPD process, such as deposition voltage, time and electrolyte concentration, were studied to determine the optimal condition for creating the nHA_PLGA coating on Mg. The nHA_PLGA coating showed a desirable thickness of $65.85 \pm 11.95 \mu \mathrm{m}$ with a complete homogenous coverage on $\mathrm{Mg}$ substrates when the deposition voltage of $75 \mathrm{~V}$ was applied for 6 minutes using an electrolyte containing $1 \mathrm{mg} / \mathrm{mL} \mathrm{nHA}$ and $0.2 \mathrm{mg} / \mathrm{mL}$ PLGA in acetone. The characterization of the coating confirmed the presence of both nHA and PLGA.
\end{abstract}

\title{
Key words
}

Biomaterials, Biodegradable Magnesium Implants, Nanocomposites, Nanophase Hydroxyapatite (nHA), Poly(lactic-co-glycolic acid) (PLGA), Electrophoretic Deposition. 


\section{Introduction}

Fixation devices, such as plates, screws, and pins, are widely used for stabilizing bone fractures and are currently made out of permanent metals, such as titanium-based alloys. However, these fixation devices are only needed temporarily in the body, and permanent metals often require surgical removal after bone heals[1]. Magnesium $(\mathrm{Mg})$ and its alloys are biodegradable in the body, which are promising for temporary implant applications. Moreover, $\mathrm{Mg}$ provides similar elastic modulus and yield strength, i.e., $40 \mathrm{GPa}$ and $126 \mathrm{MPa}$ respectively, as those of natural cortical bone (3-20 GPa and 104.9-114.3 MPa, respectively)[2]. Thus, Mgbased implants reduce the detrimental effects of stress-shielding while providing necessary strength for bearing load[3].

Nanophase hydroxyapatite (nHA) resembles the inorganic component of bone [4] and thus is considered as an attractive coating material for skeletal implants. In particular, nHA has been known for promoting adhesion and proliferation of osteoblasts (i.e., bone-forming cells)[5] and osteogenic functions of bone marrow derived mesenchymal stem cells[6], which is beneficial for bone healing. Biodegradable polymer, such as poly(lactic-co-glycolic acid) (PLGA), could improve the nHA coating adhesion on Mg-based substrates[7], when used in combination with nHA. The main degradation products of PLGA are lactic acid and glycolic acid, which can be naturally metabolized in the human body[8]. Moreover, the acidic degradation products of PLGA may be able to neutralize the $\mathrm{OH}^{-}$ions released during $\mathrm{Mg}$ degradation, thus mediating local $\mathrm{pH}$.

Electrophoretic deposition (EPD) is compatible with complex 3-D geometry of implants and is scalable for manufacturing of implants in industry[9]. Therefore, EPD was explored for coating nHA_PLGA and nHA onto $\mathrm{Mg}$ substrates in our previous study[7]. However, the process involved an additional step of preparing nHA_PLGA spheres prior to deposition and these spheres lost their shape during the post-deposition heat treatment[10]. Therefore, the objective of this study is to create nHA_PLGA coatings on Mg substrates using a single-step EPD, and optimize the EPD parameters for nHA_PLGA composites to achieve desirable coating thickness and complete homogenous coating coverage on Mg substrates. Acetone instead of water was used as the solvent for EPD because Mg degrades in water; and acetone instead of ethanol was used because PLGA has a low solubility in ethanol. The key parameters of interest are electrolyte concentration, deposition voltage, and deposition time. 


\section{Materials and Methods}

\subsection{Preparation of $n H A \_P L G A$ and $n H A$ suspension in acetone}

The nHA particles were synthesized through a wet chemistry precipitation method with a subsequent hydrothermal treatment, as previously described[7]. To prepare the nHA_PLGA suspension for composite coating, PLGA was dissolved in acetone at room temperature under sonication (Model 97043-936, Symphony ${ }^{\mathrm{TM}}$ ultrasonic cleaner) for at least 24 hours. The PLGA concentrations were $0.2 \mathrm{mg} / \mathrm{mL}$ or $2 \mathrm{mg} / \mathrm{mL}$ in acetone. The $\mathrm{nHA}$ particles were then added into the PLGA solution, and sonicated at room temperature using a high-power probe sonicator (Model S-4000, Misonix) for 5 min with 5 seconds on and 5 seconds off to reach a homogenous composite suspension with $\mathrm{nHA}$ concentrations of $1 \mathrm{mg} / \mathrm{mL}, 2 \mathrm{mg} / \mathrm{mL}$ or $3 \mathrm{mg} / \mathrm{mL}$. An ice-bath was used to provide cooling for the composite suspension during high-power sonication. For depositing nHA coating using EPD, the nHA suspension was prepared by dispersing nHA particles in acetone without PLGA under a high-power sonication for $5 \mathrm{~min}$ at room temperature.

\subsection{Electrophoretic deposition of nHA_PLGA and nHA on Mg substrate}

$\mathrm{Mg}$ bars (99.5\%, MiniScience) were cut into 10x5x1 mm rectangular-shaped substrates and used as working and counter electrodes for the EDP process. The Mg substrates were ground using 600 grit silicon carbide abrasive paper and then cleaned by sonicating in ethanol and acetone for $15 \mathrm{~min}$ each. Conductive clamps were used to submerge half of the substrates into the nHA_PLGA or nHA suspension. The submerged 5x5x1 mm Mg substrates were in parallel to each other at a fixed distance of $10 \mathrm{~mm}$. The deposition voltage from $25 \mathrm{~V}$ to $75 \mathrm{~V}$ and the deposition time from 2 minutes to 6 minutes were investigated. After the EPD process, the coated substrates were removed from the nHA_PLGA or nHA electrolytes and dried in air at room temperature.

\subsection{Material characterization after EPD process}

The Mg substrates coated under different parameters were imaged using a digital camera after drying. The nHA_PLGA coated $\mathrm{Mg}$, which was produced at a deposition voltage of $75 \mathrm{~V}$, a deposition time of $6 \mathrm{~min}$ with electrolyte concentration of $1 \mathrm{mg} / \mathrm{ml} \mathrm{nHA}$, and $0.2 \mathrm{mg} / \mathrm{ml} \mathrm{PLGA}$, was mounted on a flat SEM holder and sputter coated with platinum/palladium at $20 \mathrm{~mA}$ for 60 seconds. The surface morphology of the nHA_PLGA coating was characterized using a scanning electron microscope (SEM; Nova NanoSEM 450, FEI) at an acceleration voltage of $10 \mathrm{kV}$. Energy-dispersive x-ray spectroscopy (EDS; Aztec, Oxford instrument) was performed at an acceleration voltage of $20 \mathrm{kV}$ to determine the surface elemental composition of the nHA_PLGA 
coated $\mathrm{Mg}$. The composite coating was removed from the $\mathrm{Mg}$ substrates and collected for further characterization. X-ray diffraction (XRD; Empyrean, PANalytical) was used to examine crystalline phase of the nHA_PLGA coating using $45 \mathrm{kV}$ and $40 \mathrm{~mA}$ at a step size of $0.02^{\circ}$. The peaks and miller indices were identified based on the international center for diffraction data (ICDD) database using HighScore software (PANalytical). Fourier transform infrared spectroscopy (FTIR, Optical 8000, Bruker) was used to characterize the chemical bonds of the functional groups in the coating.

\section{Results and Discussion}

\subsection{Optimization of nHA_PLGA composite coating}

The nHA_PLGA coating should possess a desirable coating thickness and a full homogenous coverage on the Mg substrates. According to de Groot et al., an ideal HA coating thickness would be around $50 \mu \mathrm{m}$. When the coating thickness was less than $50 \mu \mathrm{m}, 30 \%$ to $40 \%$ of the HA coating rapidly dissolved after a few months. In contrast, a thicker coating undermined mechanical properties such as fatigue strength and bonding strength[11].

In an attempt to obtain the favorable coating with full coverage and appropriate thickness, the deposition parameters, including nHA and PLGA concentration in acetone, deposition voltage and time, were investigated during the EPD process. First, the initial nHA concentration was determined by examining single-phase nHA coatings under $25 \mathrm{~V}$ for 2 minutes. The results showed that $2 \mathrm{mg} / \mathrm{mL}$ concentration of $\mathrm{nHA}$ in acetone led to the most favorable coating with homogeneous and crack-free coverage (Fig.1A1-A3). Thus, this concentration of $2 \mathrm{mg} / \mathrm{mL} \mathrm{nHA}$ was selected as the initial nHA concentration, and the initial PLGA concentration was chosen to be $2 \mathrm{mg} / \mathrm{mL}$ for the composite coatings.

While the nHA and PLGA concentrations were kept at $2 \mathrm{mg} / \mathrm{mL}$ and the deposition time was fixed at 2 minutes, the voltage was applied at $25 \mathrm{~V}, 50 \mathrm{~V}$ or $75 \mathrm{~V}$. The composite coating appeared thin and transparent at the macroscopic level even at $75 \mathrm{~V}$ (Fig. 1B). The deposition time was then increased from $2 \mathrm{~min}$ to $4 \mathrm{~min}$ or $6 \mathrm{~min}$, while the concentrations remained the same with a deposition voltage of $75 \mathrm{~V}$. The composite coating still appeared thin and transparent at 6 min macroscopically (Fig. 1C). The SEM images indicated a non-homogeneous nHA_PLGA coating on Mg (image not shown). The presence of PLGA in the suspension increased the viscosity of solution and thus the resistance of electrophoretic deposition for nHA particles. To improve the composite coating, we reduced the concentration of PLGA to 0.2 
$\mathrm{mg} / \mathrm{mL}$ and paired with 1 or $2 \mathrm{mg} / \mathrm{mL}$ of $\mathrm{nHA}$ for EPD (Fig. 1D1-D2). The most favorable composite coating on $\mathrm{Mg}$, with a full uniform coverage on the substrates and a thickness of around $50 \mu \mathrm{m}$, was achieved using $0.2 \mathrm{mg} / \mathrm{mL}$ PLGA and $1 \mathrm{mg} / \mathrm{mL} \mathrm{nHA}$ in acetone at a deposition voltage of $75 \mathrm{~V}$ for 6 minutes. The process for optimizing these parameters is summarized in Figure 2.

\subsection{Material characterization after EPD}

The nHA_PLGA composite coating, produced at a deposition voltage of $75 \mathrm{~V}$, a deposition time of $6 \mathrm{~min}$ with electrolyte concentration of $1 \mathrm{mg} / \mathrm{mL} \mathrm{nHA}$ and $0.2 \mathrm{mg} / \mathrm{mL}$ PLGA, showed a complete coverage on Mg substrates with nano-scale features (Fig.3). No major cracks were found on the composite coating as indicated in the SEM image at a low magnification (Fig.3A1). The nHA particles retained their nano-scale size after EPD process, based on the SEM image at a high magnification (Fig.3A2). Webster et al. demonstrated that nanophase HA increased osteoblast proliferation, alkaline phosphatase synthesis and calcium-containing surface deposition[5]. Thus, the retention of $\mathrm{nHA}$ in the coating is desirable for enhancing osteointegration of the implants. The nHA_PLGA composite coating showed a thickness of $65.85 \pm 11.95 \mu \mathrm{m}$, as indicated in the SEM image of cross section (Fig.3B). To reach the ideal thickness of $50 \mu \mathrm{m}$, it is necessary to fine-tune the deposition voltage and time in the future research. Cracks were visible in the cross section, but were most likely caused by the grounding process during the preparation of the cross section for SEM.

Further characterizations were conducted to identify the nHA and PLGA phase in the composite coating deposited at a voltage of $75 \mathrm{~V}$ for 6 min with $1 \mathrm{mg} / \mathrm{mL} \mathrm{nHA}$ and $0.2 \mathrm{mg} / \mathrm{mL}$ PLGA in acetone. EDS analysis was performed for the nHA_PLGA composite coating, and the major peaks of $\mathrm{Ca}$ and $\mathrm{P}$ in the coating indicated the presence of nHA, as shown in Fig. 3C. The detection of $\mathrm{C}$ and $\mathrm{O}$ suggested that PLGA was present in the coating. A very small peak of $\mathrm{Mg}$ appeared in the spectrum of the coating, indicating that the coating covered most of the $\mathrm{Mg}$ substrate. According to the XRD spectrum of the nHA_PLGA composite coating in Fig.4A, the major peaks matched that of $\mathrm{HA}$ and $\mathrm{Mg}$ references. A broad peak from crystalline phase of PLGA was also found between 20 to 30 degrees. The FTIR analysis confirmed the presence of nHA and PLGA in the composite coating (Fig.4B). Specifically, the $v_{4} \mathrm{PO}_{4}, \mathrm{O}-\mathrm{H}$, and $v_{3} \mathrm{PO}_{4}$ peaks matched the phosphorous bonds found in nHA. The $\mathrm{C}-\mathrm{O}$ stretching and $\mathrm{C}=\mathrm{O}$ stretching indicated the presence of PLGA in the composite coating. 


\section{Conclusion}

The nanocomposite coatings of nHA and PLGA were successfully deposited on threedimensional $\mathrm{Mg}$ substrates in an acetone-based electrolyte using EPD. A uniform coating without cracks was achieved using EPD at a deposition voltage of $75 \mathrm{~V}$ for $6 \mathrm{~min}$ with $1 \mathrm{mg} / \mathrm{mL}$ nHA and $0.2 \mathrm{mg} / \mathrm{mL}$ PLGA in acetone. The nanocomposite coating showed a desirable thickness of $65.85 \pm 11.95 \mu \mathrm{m}$, which can be further fine-tuned. The nHA_PLGA coated Mg provides promising properties and nano-scale surface features for the use as the next-generation biodegradable implant materials.

\section{Acknowledgement}

The authors would like to thank the U.S. National Science Foundation (NSF award 1125801), Hellman Fellowship (H.L.), the University of California (UC) Regents Faculty Fellowship (H.L.), UC-Riverside Graduate Dean's Dissertation Research Grant (Q.T.), and UCRiverside Research in Science and Engineering Program (L.R.) for financial support. The authors thank the Central Facility for Advanced Microscopy and Microanalysis at the UCRiverside for the use of SEM and EDS.

Any opinions, findings, and conclusions or recommendations expressed in this material are those of the author(s) and do not necessarily reflect the views of the National Science Foundation.

\section{Reference}

[1] M.P. Staiger, A.M. Pietak, J. Huadmai, G. Dias, Magnesium and its alloys as orthopedic biomaterials: A review, Biomaterials 27(9) (2006) 1728-1734.

[2] I. Johnson, D. Perchy, H. Liu, In vitro evaluation of the surface effects on magnesiumyttrium alloy degradation and mesenchymal stem cell adhesion, Journal of biomedical materials research. Part A 100(2) (2012) 477-85.

[3] H. Waizy, J.M. Seitz, J. Reifenrath, A. Weizbauer, F.W. Bach, A. Meyer-Lindenberg, B. Denkena, H. Windhagen, Biodegradable magnesium implants for orthopedic applications, J Mater Sci 48(1) (2013) 39-50.

[4] H. Zhou, J. Lee, Nanoscale hydroxyapatite particles for bone tissue engineering, Acta biomaterialia 7(7) (2011) 2769-81.

[5] T.J. Webster, C. Ergun, R.H. Doremus, R.W. Siegel, R. Bizios, Enhanced functions of osteoblasts on nanophase ceramics, Biomaterials 21(17) (2000) 1803-1810.

[6] J. Lock, T.Y. Nguyen, H.N. Liu, Nanophase hydroxyapatite and poly(lactide-co-glycolide) composites promote human mesenchymal stem cell adhesion and osteogenic differentiation in vitro, J Mater Sci-Mater M 23(10) (2012) 2543-2552.

[7] Q. Tian, H. Liu, Electrophoretic deposition and characterization of nanocomposites and nanoparticles on magnesium substrates, Nanotechnology 26(17) (2015) 175102. 
[8] P. Gentile, V. Chiono, I. Carmagnola, P.V. Hatton, An Overview of Poly(lactic-co-glycolic) Acid (PLGA)-Based Biomaterials for Bone Tissue Engineering, Int J Mol Sci 15(3) (2014) 36403659.

[9] A.R. Boccaccini, S. Keim, R. Ma, Y. Li, I. Zhitomirsky, Electrophoretic deposition of biomaterials, J R Soc Interface 7 Suppl 5 (2010) S581-613.

[10] Q.M. Tian, H.N. Liu, Electrophoretic Deposition and Characterization of Biocomposites on Magnesium for Orthopedic Applications, Advanced Materials Research 922 (2014) 761-766.

[11] K. de Groot, R. Geesink, C.P. Klein, P. Serekian, Plasma sprayed coatings of hydroxylapatite, Journal of biomedical materials research 21(12) (1987) 1375-81. 


\section{Figures}
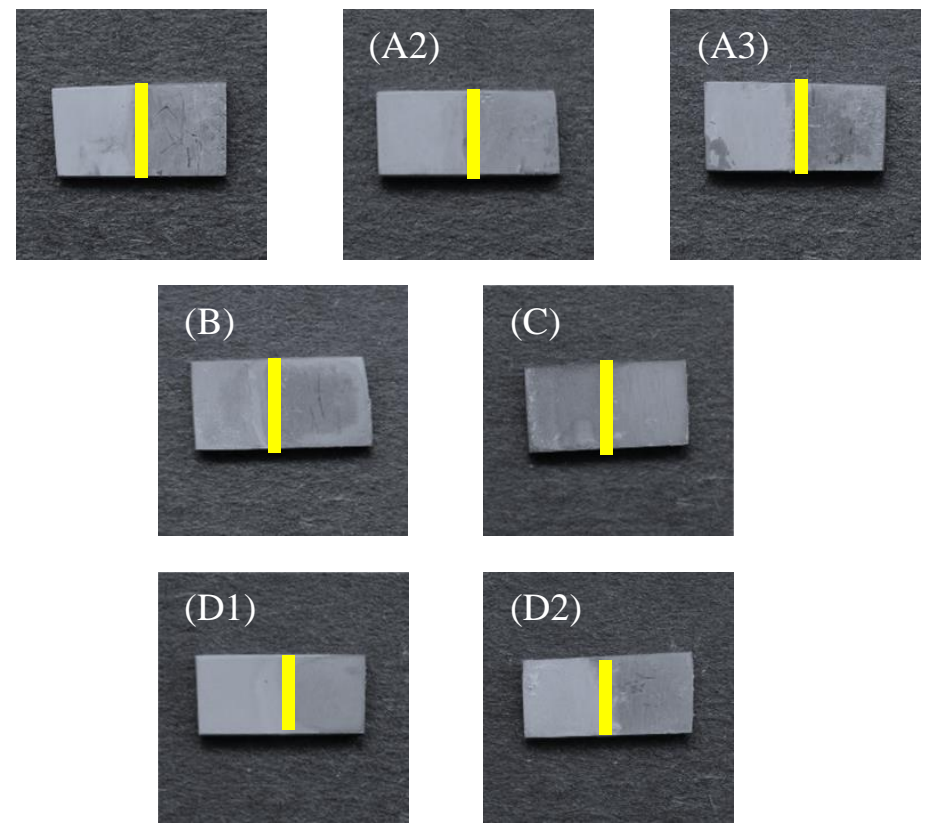

Figure 1. Macroscopic images of the nHA coating and the nHA_PLGA coating on Mg substrates electrophoretically deposited at the prescribed deposition voltage, deposition time and electrolyte concentration. The coatings are on the left side of the yellow line in each image. (A1A3) The nHA coatings were deposited at $25 \mathrm{~V}$ for $2 \mathrm{~min}$ using (A1) $1 \mathrm{mg} / \mathrm{mL}$ of nHA, (A2) 2 $\mathrm{mg} / \mathrm{mL}$ of $\mathrm{nHA}$, or (A3) $3 \mathrm{mg} / \mathrm{mL}$ of $\mathrm{nHA}$, respectively. (B) The nHA_PLGA coating was deposited at $75 \mathrm{~V}$ for $2 \mathrm{~min}$ using $2 \mathrm{mg} / \mathrm{mL}$ nHA and $2 \mathrm{mg} / \mathrm{mL}$ PLGA. (C) The nHA_PLGA coating was deposited at $75 \mathrm{~V}$ for $6 \mathrm{~min}$ using $2 \mathrm{mg} / \mathrm{mL} \mathrm{nHA}$ and $2 \mathrm{mg} / \mathrm{mL}$ PLGA. (D1-D2) The nHA_PLGA coatings were deposited at $75 \mathrm{~V}$ for $6 \mathrm{~min}$ using (D1) $1 \mathrm{mg} / \mathrm{mL}$ of nHA or (D2) 2 $\mathrm{mg} / \mathrm{mL} \mathrm{nHA}$, respectively, and $0.2 \mathrm{mg} / \mathrm{mL}$ PLGA. 


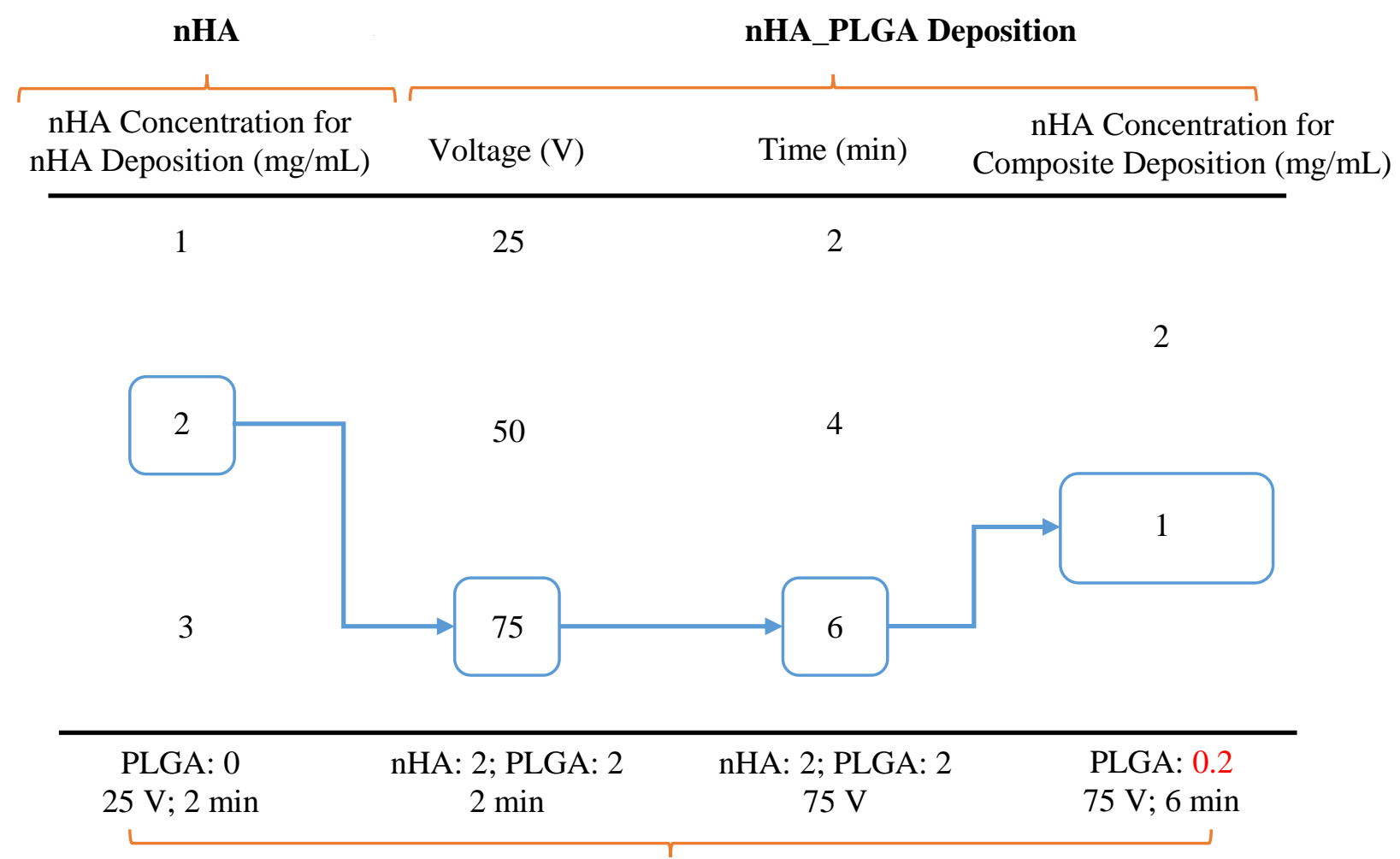

Fixed Parameters during EPD

Figure 2. Summary of optimization process of EPD parameters for nHA_PLGA coating on $\mathrm{Mg}$ substrates. The deposition voltage was tested at $25 \mathrm{~V}, 50 \mathrm{~V}$, or $75 \mathrm{~V}$. The deposition time was tested at $2 \mathrm{~min}, 4 \mathrm{~min}$, or $6 \mathrm{~min}$. The nHA concentration in electrolyte was tested at 1 $\mathrm{mg} / \mathrm{mL}, 2 \mathrm{mg} / \mathrm{mL}$ or $3 \mathrm{mg} / \mathrm{mL}$ for $\mathrm{nHA}$ deposition, and the $\mathrm{nHA}$ concentration in electrolyte was tested at $1 \mathrm{mg} / \mathrm{mL}$ or $2 \mathrm{mg} / \mathrm{mL}$ for nHA_PLGA composite deposition. The PLGA concentration in electrolyte was tested at $0.2 \mathrm{mg} / \mathrm{mL}$ or $2 \mathrm{mg} / \mathrm{mL}$. 

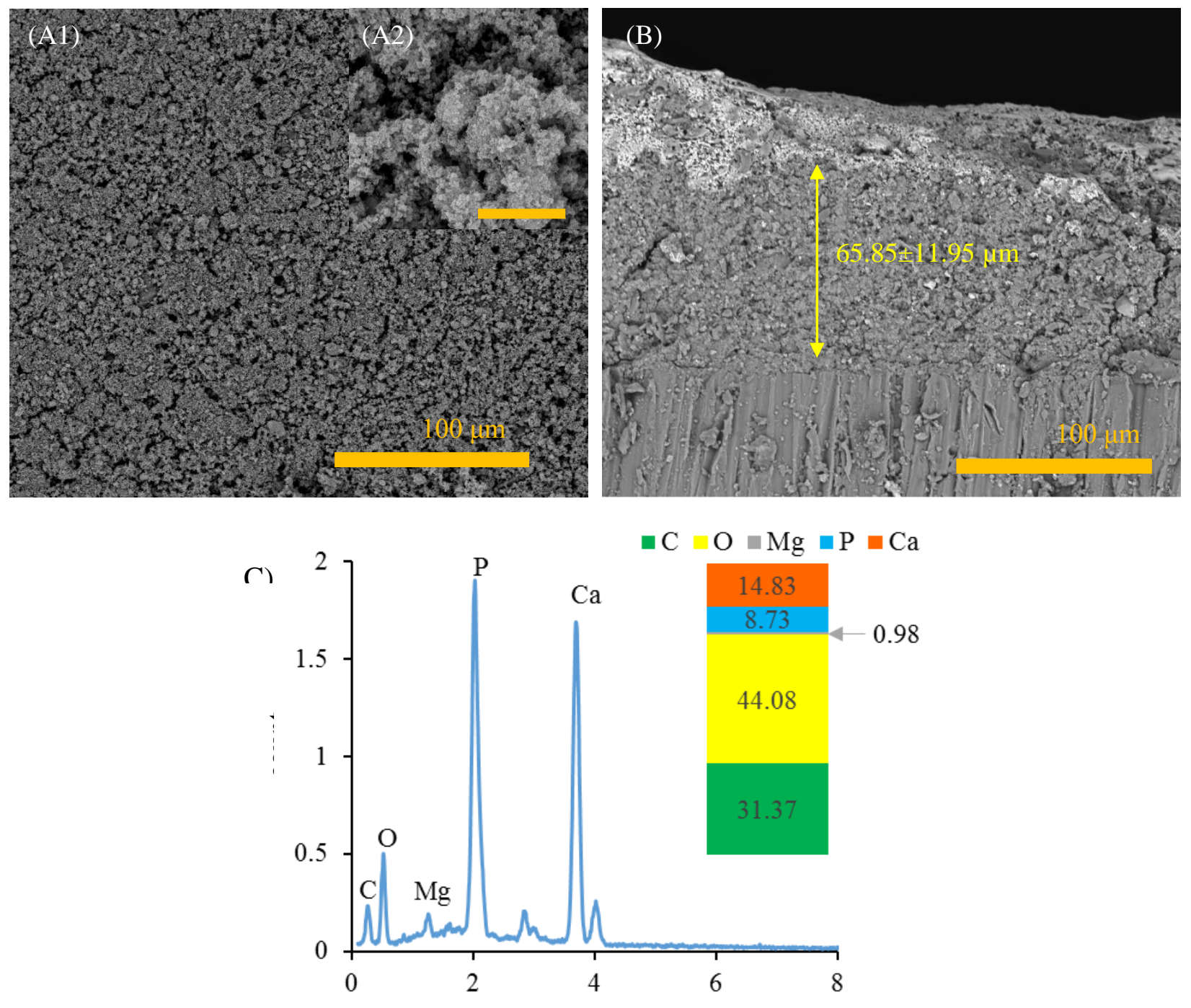

Figure 3. Surface morphology, cross section and elemental composition of the nHA_PLGA coated Mg sample, produced at a deposition voltage of $75 \mathrm{~V}$, a deposition time of 6 min with the electrolyte concentration of $1 \mathrm{mg} / \mathrm{mL} \mathrm{nHA}$ and $0.2 \mathrm{mg} / \mathrm{mL}$ PLGA in acetone. (A1A2) SEM images of nHA_PLGA coating on Mg substrate at (A1) low magnification and (A2) high magnification. (B) SEM image of the cross section of the nHA_PLGA coating on Mg substrate. (C) EDS spectrum and elemental composition (wt. \%) of nHA_PLGA coated Mg substrate, which was performed on (A1). The original magnification of the SEM images was $500 \mathrm{x}$ for (A1) and (B), and 10,000x for (A2). 

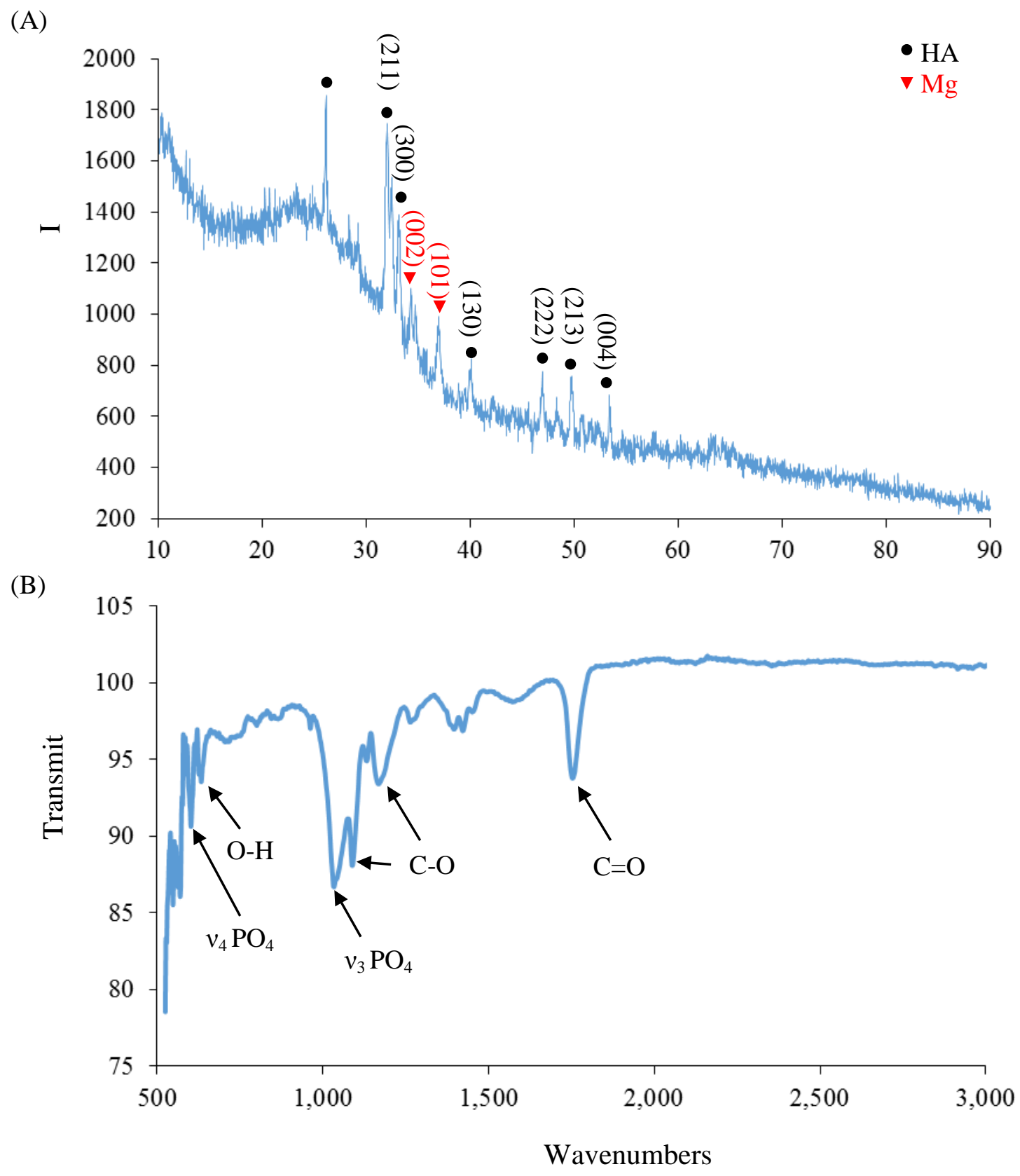

Figure 4. Phase composition and chemical bonding of nHA_PLGA coated Mg sample, which was produced at a deposition voltage of $75 \mathrm{~V}$, deposition time of 6 min with the electrolyte concentration of $1 \mathrm{mg} / \mathrm{mL}$ nHA and $0.2 \mathrm{mg} / \mathrm{mL}$ PLGA in acetone. (A) XRD spectrum of nHA_PLGA coated Mg. Black dots indicate HA peaks with their indices and red triangles indicate Mg peaks with their indices. (B) FTIR spectrum of nHA_PLGA coated Mg. 
Optimization of nHA_PLGA Coating on Mg-based Implants via One-Step Electrophoretic Deposition

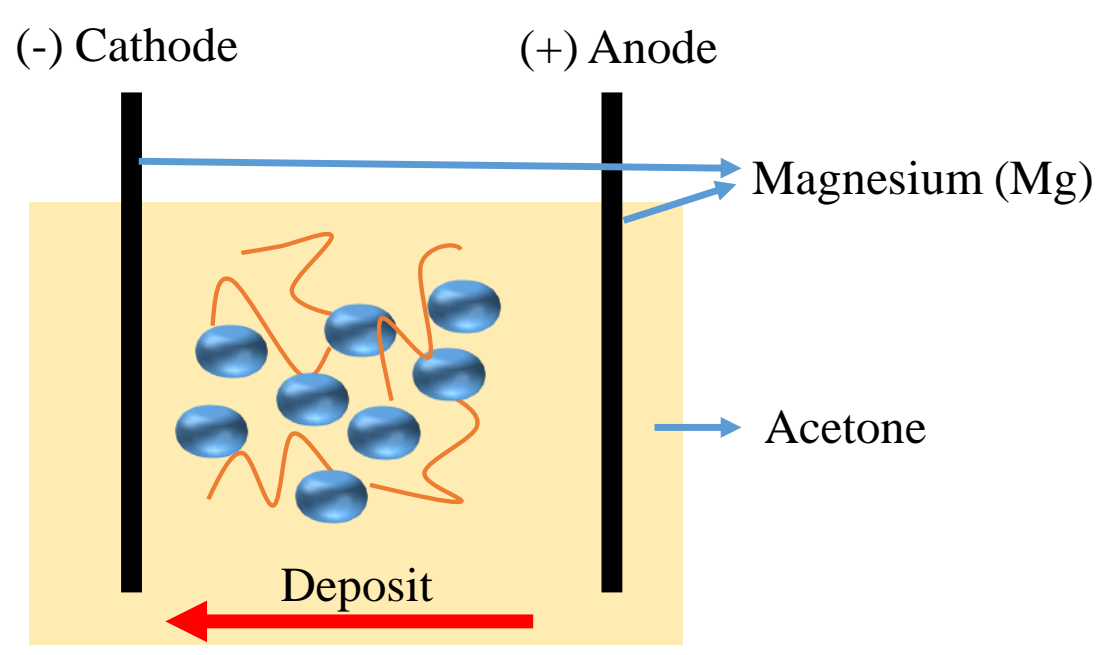

Nanophase Hydroxyapatite (nHA)

Poly (Lactic-co-Glycolic Acid) (PLGA)

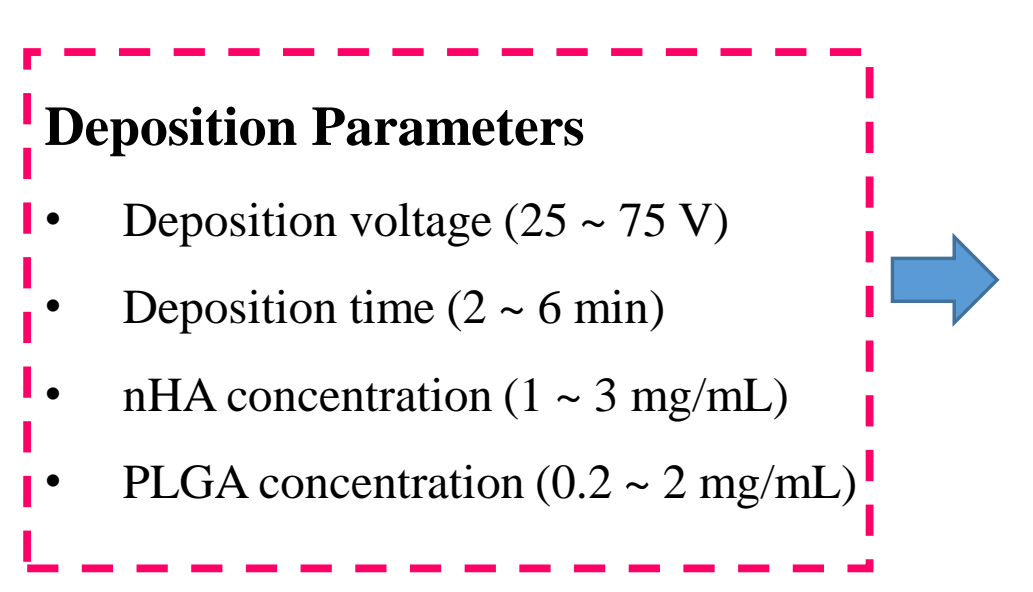

I - - - - - - - - - - - - - -

\section{Favorable Parameters}

Deposition voltage of $75 \mathrm{~V}$, deposition time of 6 min, nHA concentration of 1 $\mathrm{mg} / \mathrm{mL}$ and PLGA concentration of 0.2 $\mathrm{mg} / \mathrm{mL}$

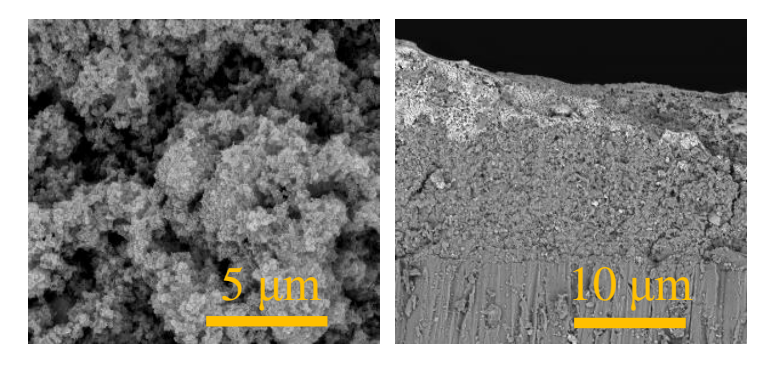

nHA_PLGA coating on Mg 